\title{
Teaching Lexis through Comics: An Exploratory Study
}

\author{
M Vijaya Lakshmi \\ Assistant Professor of English Gudlavalleru Engineering College
}

\begin{abstract}
The present study has been carried out with the main objective of exploring how lexis can be taught through comics using the lexical approach. The objectives of the present paper are four fold: first, it provides an introduction to the lexical approach. Secondly, it describes the concept of 'lexis' by taking into account various definitions on the term. Thirdly, it highlights the advantages of using comics to teach lexis. Fourthly, it includes a few exercises and activities for the chunks which have been identified in the comics to aid learners in reinforcing the lexical chunks in their mental lexicon.
\end{abstract}

\section{Introduction}

A few decades ago, there was a predominant view in the linguistic circles that vocabulary was subservient to grammar. Linguists at that time strongly supported the dichotomy of grammar and vocabulary and they preferred to lay emphasis on the structures of language rather than the words. Also, they were of the view that acquisition of a language is dependent on the mastery of grammatical rules of the language and vocabulary is of secondary importance.

But during the 1990's there was an increased interest in vocabulary teaching and learning. The book Teaching and Learning Vocabulary (1990) by Paul Nation provided useful insights into vocabulary acquisition and it extended guidance on classroom pedagogy. At the same time, the advent of corpus linguistics and the COBUILD project of John Sinclair (1987) gave new impetus to theories on language acquisition. Sinclair's book Corpus, Concordance, Collocation (1991) and other corpus based studies shed new light on how language works and this led to a new understanding and description of language. Also, these studies revealed the widespread occurrence of multi-word units or lexical chunks in native speakers' language. The studies then put forward a theory that is almost contrary to Chomskyan theory of language which holds that native speakers have a capacity of creating and interpreting unique sentences which they have never heard or produced previously.

But with the advent of corpus based analyses, many linguists departed from the Chomskyan view to uphold the new theory of language.

With the publication of the book The Lexical Approach: The State of ELT and a Way Forward in 1993, there was a shift from the traditional approaches to a lexis based approach.

\section{Lexical Approach}

Lexical Approach to language teaching is based on the principles that language consists primarily not of grammatical structures/patterns but of lexical units. To quote Lewis, this approach focusses on developing learner's proficiency with lexis, or word and word combinations. (1993:95).

He holds that native speakers store chunks in their mental lexicon to retrieve and use them in their language. Also, he states that the ability to chunk language successfully is central to an understanding of how language works. For this reason, Lewis suggests that language teaching should include the teaching of lexis or chunks. In fact, he advocates that lexis/ lexical phrases in any language offer more communicative and expressive power than grammatical structures.

\section{Lexis}

Though the terms lexis and vocabulary are often stated in the same context and mostly treated as synonyms, there exists a difference in meaning between these two terms and they are not one and the same. The distinction will be made clear by making a note of these definitions put forward by two advocates:

Lexis is a more general word than common vocabulary. Vocabulary is often used to talk of the individual words of language; lexis covers single words and multi-word objects which have the same status in the language as simple words, the items we store in our mental lexicons ready for use.

(Lewis1997:217)

Lexis includes not only the single words but also the word combinations that people store in their mental lexicons. (Olga 2001:1) 
Although the lexical items are of different kinds, Lewis identifies them as falling into four types:

1. Words and Polywords -- Words include all the essential vocabulary for learners to memorize (book, pen, etc.) Polywords is a small group of lexical items which fall between words and major multi-word categories. For instance, bread and butter.

2. Collocations - Word and word combinations (take an exam, heavy rain etc.)

3. Fixed expressions - The chunks which are comparatively rare and short and are mostly used in spoken language (Have a nice day and How do you do?)

4. Semi-Fixed expressions - The expressions that range from 'very short to very long' (Its/That's right, Looking forward to hearing from/seeing/meeting you.)

\section{Advantages of using comics in teaching lexis}

Comics have proved to be a rich source of the lexical categories identified in the lexical approach. They contain natural, conversational English that is comprehensible. Also, they provide us an excellent opportunity for exposure to authentic language.

\section{Method of Research}

For the present research, initially, 6 Tinkle Magazines and 6Tinkle Digests have been read. Thereafter, 6 stories have been selected for the study based on the presence of the lexical chunks. A total of 55 chunks have been identified in the six stories selected for this study. These chunks later have been categorized according to the classification advocated by Lewis. After categorizing them, exercises and activities have been devised to reinforce the chunks in the learners' mental lexicon.

The main objective of all the exercises and activities included in the paper is to raise the lexical awareness of the learners which is eventually expected to lead to their increased lexical competence.

\section{Exercises and Activities on Polywords}

This study identifies eighteen polywords from the comics selected for the study. The polywords are subdivided into two categories, namely, expressions of time and phrasal verbs. In addition to this, exercises and activities are designed exclusive to teach polywords.

\section{Exercise1:}

Match the words in column A with the words in column B to form expressions of time.

\begin{tabular}{|l|l|}
\hline 1. After a few & a) Time \\
2. In no & b) few months \\
3. Within a & c) many days \\
4. After & d) months \\
\hline
\end{tabular}

Activity1: Instruct the learners to sit in groups to discuss and write at least ten expressions of time they had encountered in the past. Ask a member from each group to read out their expressions to the whole class.

\section{Exercise 2:} sentence.

Choose the right expression of time from the two options in the brackets to make a meaningful

1. Can you please meet me after

2. You will have to go to music classes from (later/sometime)

3. You shall submit your report .(on this day/ today onwards.

4. __ he was called to give a report on the project. (the next day/ tomorrow)

Activity2: Provide the learners with a comic story to spot out the expressions of time and underline them and label them as polywords. Also, ask any one learner in the class to read out what she/he has noticed. If the learner has overlooked any, others can add to the existing list.

\section{Exercises and Activities on Collocations}

The present study lists down 30 collocations identified from the six comics chosen for the study. It classifies these collocations into three types based on their word-partnership. The categorization is as follows:
1. Adjective+ Noun
2. Verb+ Noun
3. Verb+ Adjective 
Exercises and activities are also devised to ensure the learning of these collocations which in turn assist the learners to develop their collocational competence.

\section{Adjective + Noun Entries}

Exercise 3:

Fill in the blanks with the collocations given in the box to make acceptable sentences.

\begin{tabular}{|lll|}
\hline $\begin{array}{l}\text { long queue } \\
\text { precious time } \\
\text { great difficulty }\end{array}$ & magnificent bird & bare necessities \\
& unsuccessful attempt & $\begin{array}{l}\text { precious possession } \\
\text { new invention }\end{array}$ \\
\hline
\end{tabular}

1. I wasted my and now I cannot get it back.

2. Chris Ria is a and his songs are liked by many.

3. There are many people who do not even have

4. As today is the last day for paying fee, there is a of life.

5. I tried my best to get through the exam, but that was as

6. He had to face many hardships to launch his at the bank.

7. With a in the market.

8. Ram saw a he gained admission to that university.

Activity 3:

Ask the learners to sit in groups. Ask them to find out the parts of speech of the collocations. Then, instruct them to refer to a collocation dictionary to provide one possible combination for the words time, singer, necessities, queue, attempt, invention, difficulty, bird, possession.

\section{Exercise 4:}

Choose the right collocation from the two options to make a meaningful utterance.

1. The couple had a joyful/enjoyful reunion after a break up.

2. This is the most wonderous/ wonderful horse I have ever seen.

3. He dreamt of building a fine/ vast mansion to gift his wife.

4. You cannot expect her to be healthy in his advancement/ advancing age.

5. Her pale face is an indication of her failing/falling health.

6. The villagers witnessed some strange/ eccentric birds in their fields.

7. I was in a deepest/ deep sleep when you called me.

8. This is a bad/ ill period of my life.

9. Mutual funds are one of the magnificent/ best investments.

10. Though he is a learning/ learned man, he is ill- mannered.

Activity 4: Make the learners sit in a circle. Instruct them to play musical chairs. Ask one learner to go around the circle with one word written on a slip of paper. Let him drop the paper at the back of one learner. The learner has to pick up the paper and write at least two collocations. On failing to do it, the learner will be excluded from the group.

\section{Verb+ Noun Entries}

Exercise 5:

Choose the right word from the options to make correct collocation.

1. I will deal with the college to work in the evenings.
a) do
b) perform
c) make
d) frame
2. She pride
nouncing
her's name.
a) give
b) make
c) offer
d) took

3. The verger made a living by

$\begin{array}{llll}\text { a) offering b) arranging c) praying } & \text { d) strike }\end{array}$

4. Her dream was to a living as a singer.
a) do
b) carry on
c) make
d) endure

5. He wandered all over the city to find a suitable location to
a) Cherish
b) give
c) expand
d) accept

6. Ram went to his fortune in the U.S.A. his business. 

a) do
b) make
c) perform
d) take

Activity 5: Form the learners into groups. Ask them to nominate the leader for their groups. Instruct the leader for their groups. Instruct the leader of a group to come to the board and make him face the board. Ask the leader to provide verbs to the nouns given to him. Whoever provides correct verbs to the nouns given will be declared the winner.

\section{Verb + Adjective Entries}

Fill in the missing letters to form meaningful collocations by using the letters in the brackets.

1. $\mathrm{G}_{--} \mathrm{re}_{--} \mathrm{y}(\mathrm{t}, \mathrm{e}, \mathrm{a}, \mathrm{d})$

2. $\quad \mathrm{L}_{-} \mathrm{kt}_{-} \mathrm{ub}_{-} \_\mathrm{d}(\mathrm{o}, \mathrm{r}, \mathrm{o}, \mathrm{l}, \mathrm{o} e)$

3. Be o_e e $_{-}$ci $\_$ed $(\mathrm{m}, \mathrm{c}, \mathrm{x}, \mathrm{t})$

4. $\quad \mathrm{F}_{-} \mathrm{e}_{-} \mathrm{c}_{-} \mathrm{m}_{-} \mathrm{or}_{-} \mathrm{b}_{-} \mathrm{e}(\mathrm{e}, \mathrm{o}, \mathrm{l}, \mathrm{f}, \mathrm{t}, \mathrm{l})$

Activity6: Instruct the students to frame meaningful sentences using the collocations above. Ask a few learners to read out their sentences.

\section{Exercises and Activities on Fixed Expressions}

The study identifies 13 fixed expressions from the stories selected for the study. It categorises these expressions based on the number of words present in them. It names them as two worded, three worded and five worded fixed expressions.

Exercise 6: Complete the conversations given below using the fixed expressions from the box.

well done well enough of course why not what's wrong

1. A: Hai Ram.

B: Hai Syam

A: Where have you been all these days?

B: I have been to Delhi to play a cricket match.

A:Oh. Is that?

B:B:Yes. And, I was awarded the best player of the match.
A:Oh Keep it up.
B: Thank you.

2. A: Hello Tom

B: Hai Sam

A: _ ? You look so glum.

B: I secured a low grade in my assignment.

A: Come on Tom! Don't worry. Try hard for a better grade next time.

B: O.K

3. A: Mary, will you step in my cabin? I have something to say you?

B: $\longrightarrow$ sir. I will.

4. A: Ravi, how did you manage to complete your assignment in time?

B: _ my sister helped me in various ways to complete my assignment. Thanks to her.

5. A: Hello Amy, can you please help me cleaning my room?
B: ? I love to help you.
A: Thank you
B: Welcome.

Activity 7: Give the learners a comic story/strip that contains two worded fixed expressions. Instruct them to read and underline them. Ask the learners to use hem in contexts of their own.

Exercise 7: Match the words in column A with the words in column B to make correct fixed expressions.

\begin{tabular}{l|l} 
1. you are & a. know \\
2. have no & b. right? \\
3. is this & c. worries \\
4. let me & d. amazing
\end{tabular}


Activity 8: Try to translate these sentences into your mother tongue. Can you think of equivalents to these expressions in your mother tongue?

Exercise 8: Put the words in an order to make acceptable fixed expressions.

1. you what's matter the with?

2. name up live to its

3. that hear I'm to sad

Activity 9: Instruct the learners to read a comic story you provided them with and ask them to underline the five worded fixed expressions in it.

\section{Exercises and Activities on Sentence Heads}

Exercise 9: Insert the right sentence heads in the blanks using the ones given in the box.

\begin{tabular}{|ll|}
\hline It was said that & Troubled by his thoughts \\
Now that he was old & We now call upon \\
When he awoke & As you may have heard \\
The good part is that & One day while he was \\
As a matter of fact & But this is nothing \\
\hline
\end{tabular}

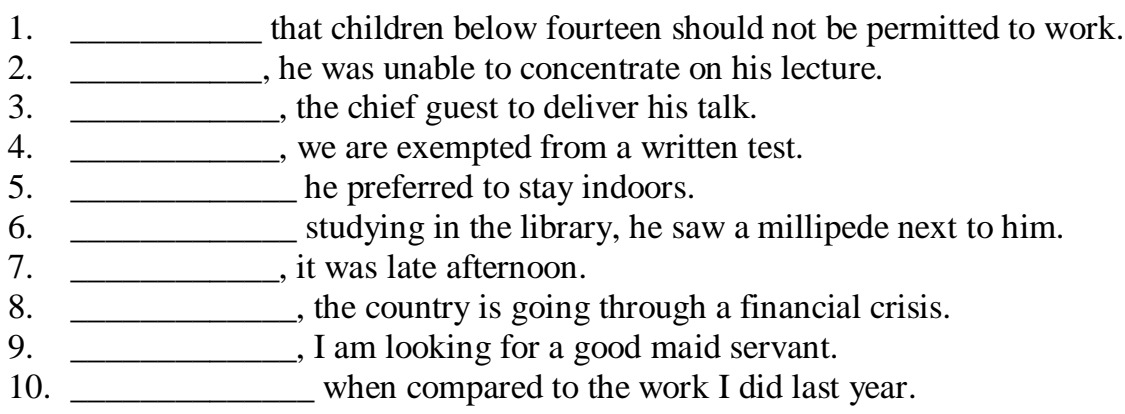

Activity 10: Ask the learners to sit in groups. Hand over to them a slip of paper with three sentence heads at least. Write their continuations also on slips of papers and give them to other groups. Now ask the learners to go around the class to interact with other learners to find out the correct sentences. While the group with sentence heads tries to find out the correct combinations, the groups with possible combinations search for the right sentence heads.

In conclusion, the study had observed that one of the best sources to teach lexis by taking the aid of lexical approach. The study has also observed that authentic texts like comics are a rich source of all kinds of lexical chunks. The study recommends that comics be incorporated into the curriculum as they are highly effective in breaking the monotony that crops up during the process of teaching/learning a language.

\section{Works Cited}

1. Lewis, M. The Lexical Approach: The State of ELT and A way Forward. Hove, England: Language Teaching Publications, 1993.

2. __ Implementing the Lexical Approach. Hove, England: Language Teaching Publications, 1997.

3. Teaching Collocation: Further Developments in the Lexical Approach. London: Language Teaching Publications.2000.

4. Moudraia, O. "Lexical Approach to Second Language Teaching". ERIC Digest. June 2001.web.10 October 2007. http://www.cal.org/resources/digest/0102/lexical.htm

5. McCarthy,M and F.O’Dell. English Collocations in Use Cambridge: CambridgeUP, 2005.

6. Tinkle Digest 2009, No: 210: Mumbai: Amar Chitra Katha Pvt.Ltd.

7. Tinkle Digest 2009, No: 205: Mumbai: Amar Chitra Katha Pvt.Ltd.

8. Tinkle Digest, No: 42: Mumbai: Amar Chitra Katha Pvt.Ltd.

9. Tinkle Magazine, 2010 No: 569: Mumbai: Amar Chitra Katha Pvt.Ltd.

10. Tinkle Magazine, 2010 No: 573: Mumbai: Amar Chitra Katha Pvt.Ltd.

11. Tinkle Magazine, 2010 No: 577: Mumbai: Amar Chitra Katha Pvt.Ltd. 